(C) 2007 IEEE. Personal use of this material is permitted. Permission from IEEE must be obtained for all other uses, in any current or future media, including reprinting/republishing this material for advertising or promotional purposes, creating new collective works, for resale or redistribution to servers or lists, or reuse of any copyrighted component of this work in other works. 


\section{Comparative Study of High-Speed PM Motors with Laminated Steel and Soft Magnetic Composite Cores}

\author{
Yunkai Huang, Qiansheng Hu, Jianfeng Zhao \\ School of Electrical Engineering \\ Southeast University \\ Nanjing, China \\ huangyk@seu.edu.cn
}

\author{
Jianguo Zhu, and Youguang Guo \\ Faculty of Engineering \\ University of Technology, Sydney \\ Sydney, Australia \\ joe@eng.uts.edu.au
}

\begin{abstract}
Soft magnetic composite (SMC) material is formed by surface-insulated iron powder particles, and has very low eddy current. To explore the application of SMC materials, two types of high-speed (20krpm) permanent magnet (PM) motor have been designed and constructed. One employs radial flux type with laminated steel core, and the other employs transverse flux type with SMC core. Considering the importance of core loss in high speed motors, laminated steel and SMC material are tested by 2-D magnetic tester, and rotational core loss model is employed in the core loss calculation. Details of machine geometry and design procedure are described and some features of the machines are compared.
\end{abstract}

Keywords- core losses, finite element analysis (FEA), highspeed, radial flux, soft magnetic composite (SMC) materials, transverse flux

\section{INTRODUCTION}

Soft magnetic composite (SMC) materials are very suitable for application in permanent magnet motors with complex structures, 3D magnetic flux paths, and high operating frequencies, because of their unique properties such as magnetic and thermal isotropy, low eddy current loss, and suitability for complex net shape manufacturing by highly matured powder metallurgical technology. To investigate the application potential of SMC materials in electrical machine, a great number of efforts have been made to employ SMC in various types of motor, such as claw pole motor [1-3], transverse flux motor [4-6], axial flux motor [7, 8], universal motor $[9,10]$ and so on. The previous works basically focus on the SMC materials' properties of magnetic isotropy and suitability for complex structure. This paper will explore the application of SMC materials in the high speed area.

Compared with conventional general-purpose motors, the major advantages of high speed motors include smaller size under a given power, smaller moment of inertia and faster response, and direct connection with other high speed mechanical devices without gears. The operational frequency of high speed motors is normally over $1000 \mathrm{~Hz}$, and even 5000 $\mathrm{Hz}$ for super-high speed motors. Because of low eddy current, SMC material is an ideal candidate as the core.

Two types of high-speed permanent magnet motor with the same dimensions have been designed and constructed in this paper. One is transverse flux machine with SMC core, and the other is radial flux machine with laminated steel. They are compared to each other based on design and manufacture methods, performance and cost to verify the SMC material properties on high frequency and show the potential of the material.

\section{TRANSVERSE FLUX MACHINE WITH SMC CORE}

\section{A. Structure and Dimensions}

The topology of transverse flux machine is illustrated in Fig. 1. The stator consists of the claws, the yoke and the coil. To build the three-phase motor, three single-phase motors are stacked together in the axial direction. The three stator stacks are shifted by 120 electrical degrees to each other to achieve a smooth torque. Because of the complex geometry, the magnetic field in a transverse flux machine is truly three-dimensional (3$\mathrm{D})$, and the armature carries significant field in all three directions. On the other hand, the claw pole structure is difficult to manufacture using laminated steel. The manufacturing process can be simplified by using injection/compaction molding technique and hence SMC material is very suitable for this structure. All claw poles can be formed in a die and there is no further mechanical processing required. Table I lists the key dimensions and parameters. The motor main size, including the stator outer diameter and axial length of one stack, are basically determined by the dimension of available SOMALOY ${ }^{\mathrm{TM}} 500$ preforms.

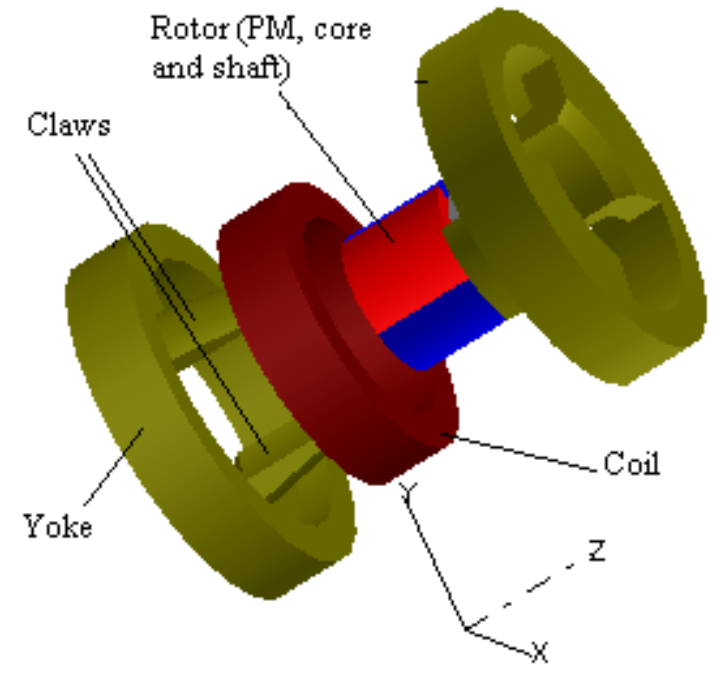

Figure 1. Magnetically relevant parts of one phase SMC motor 
TABLE I. Key Dimensions AND DESIGN PARAMETERS OF SMC MOTOR

\begin{tabular}{|l|l|}
\hline \multicolumn{1}{|c|}{ Dimension } & Value \\
\hline Number of phases & 3 \\
\hline Rated power (W) & 2000 \\
\hline Rated frequency (Hz) & 666.7 \\
\hline Rated speed (rev/min) & 20000 \\
\hline Number of poles & 4 \\
\hline Stator core material & SOMALOY $^{\mathrm{TM}} 500$ \\
\hline Stator outer diameter (mm) & 78 \\
\hline Rotor core material & $\mathrm{SOMALOY}^{\mathrm{TM}} 500$ \\
\hline Rotor outer diameter (mm) & 29 \\
\hline Rotor inner diameter (mm) & 18 \\
\hline Permanent magnets & NdFeB \\
\hline Magnet arc & $75^{\circ}$ \\
\hline Magnet radial length (mm) & 2 \\
\hline Airgap radial length (mm) & 1 \\
\hline Motor axial length (mm) & 48 \\
\hline
\end{tabular}

\section{B. 3-D Magnetic Field Analysis}

Since the transverse flux machine has 3-D magnetic flux, it is necessary to use 3-D finite element analysis (FEA) for accurate determination of its parameters and performances. By taking advantage of the periodical symmetry, only one pole pitch region of machine, as shown in Fig. 2, needs to be calculated. At the two radial boundary planes, the magnetic scalar potential obeys the half-periodical boundary conditions.

Fig. 3 shows the no-load magnetic distribution for when magnets align with claws and the stator winding links the maximum magnetic flux. The winding flux can be computed by the surface integral of magnetic density after the magnetic field distribution is solved by FEA. For this motor, the computation is based on the middle cross-sectional area of the stator yoke. As the rotor rotates, the winding flux varies and an electromotive force (EMF) is induced. The EMF frequency depends on the rotor speed, while the EMF waveform is determined by the waveform of the winding flux. At no-load, the winding flux waveform is calculated, as shown in Fig. 4. It is nearly a triangular waveform when the number of poles is 4 , and as the number of poles increases, it will become close to sinusoidal.

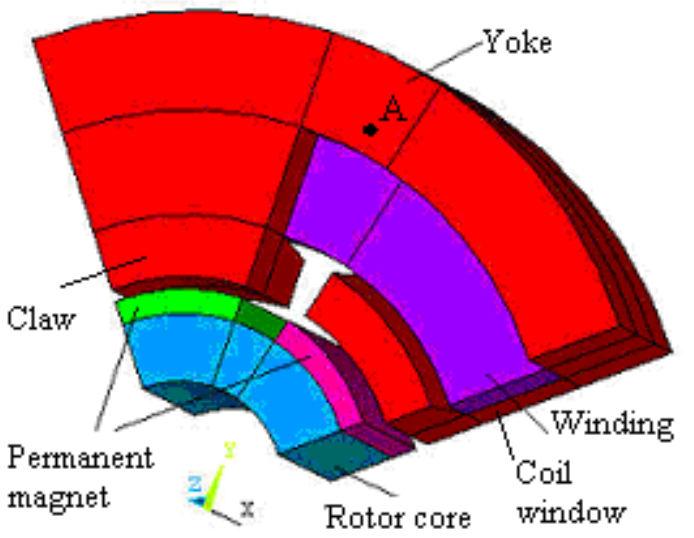

Figure 2. Region of SMC motor for field solution

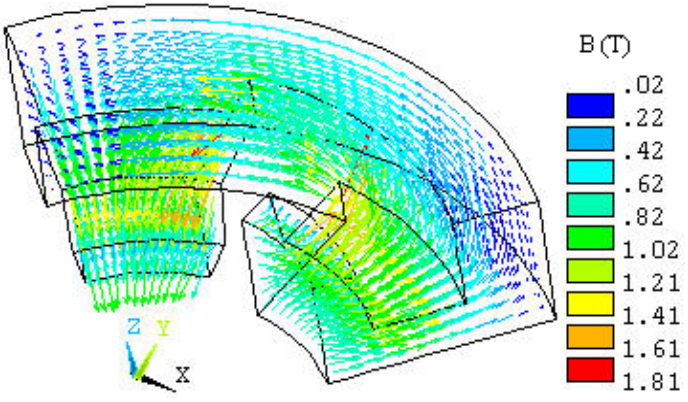

Figure 3. Vector plot of no-load flux density of SMC motor

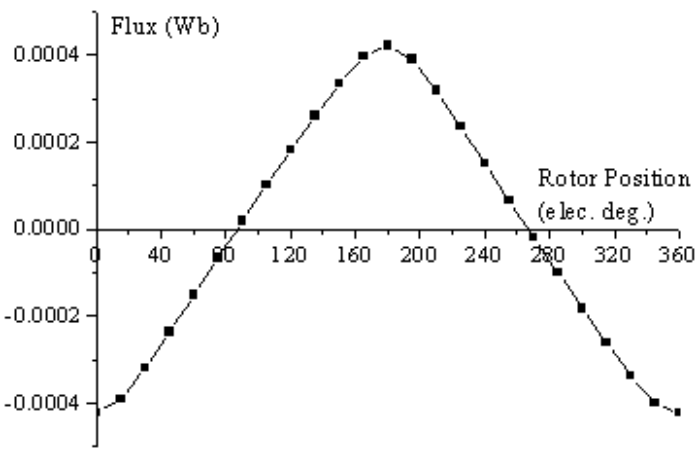

Figure 4. Winding flux waveform of SMC motor at no-load (one turn)

\section{RADIAL FLUX MACHINE WITH LAMINATED STEEL}

\section{A. Structure and Dimensions}

Fig. 5 shows the structure of the designed permanent magnet brushless motor. Many types of rotor structure are proposed by many researchers, in high-speed application, a canned rotor type is preferred because its simple structure makes it easy to manufacture and robust to overcome the centrifugal force. The non-magnetic can encloses 4-pole permanent magnet with cylindrical construction. The main dimensions of laminated steel motor are the same as the SMC motor, tabulated in Table I, except that the stator and rotor core material is DW310-35 (0.35mm electrical steel).

\section{B. 2-D Magnetic Field Analysis}

2-D FEA is used to calculate the performance and parameters of the motor. Fig. 6 shows the no-load flux density and flux line. To reduce the core loss, the average value of the flux density in stator core is designed below $1.0 \mathrm{~T}$, and the same principle is used in the design of SMC motor. Fig. 7 is the winding flux waveform against the rotor position.

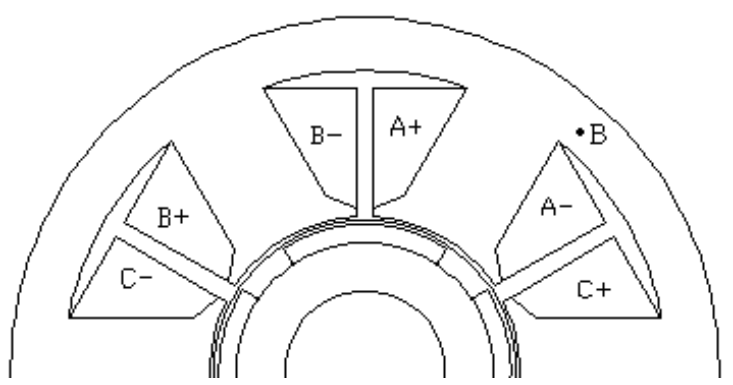

Figure 5. Cross-section of permanent magnet brushless motor 


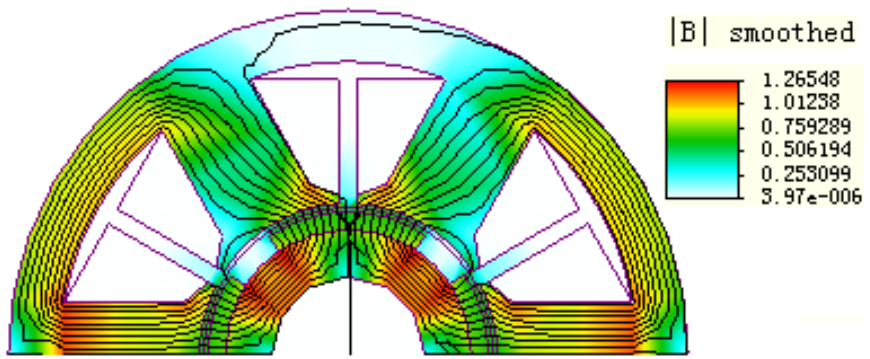

Figure 6. Shaded plot of no-load flux density and flux line of laminated steel motor

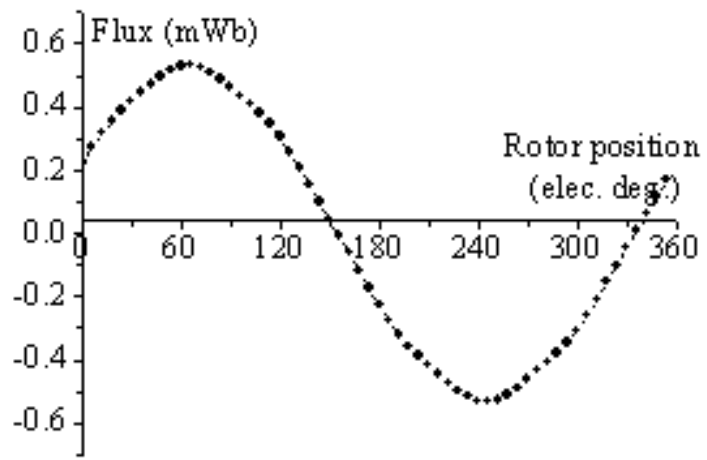

Figure 7. Winding flux waveform of laminated steel motor at no-load (one turn)

\section{CORE LOSS}

Core loss is crucial for high-speed motor because the core loss is the dominant component of power loss due to high operating frequency. An accurate model included rotational core loss described in [11] is applied for predicting the core loss in the 3-D flux SMC motor and 2-D flux laminated steel motor. The total core loss is computed based on time-stepping finite element analysis by separating hysteresis, eddy current and anomalous losses in each element under the alternating and rotational magnetic fields.

For alternating core loss modeling, a standard practice is to separate the loss into the following three components: hysteresis, eddy current and anomalous losses:

$$
P_{a l t}=K_{a h} f B_{m}{ }^{h}+K_{a e}\left(f B_{m}\right)^{2}+K_{a a}\left(f B_{m}\right)^{3 / 2}
$$

where $B_{m}[\mathrm{~T}]$ is the peak value of flux density, $f[\mathrm{~Hz}]$ is the frequency, and $K_{a h}, h, K_{a e}, K_{a a}$ are the loss coefficients for the alternating hysteresis, eddy current and anomalous losses, respectively.

Similarly, the specific circular core loss can also be separated into three parts, as expressed in (2).

$$
P_{r o t}=P_{r h}+K_{r e}\left(f B_{m}\right)^{2}+K_{r a}\left(f B_{m}\right)^{3 / 2}
$$

where $P_{r h}$ is the rotational hysteresis loss, $K_{r e}$ and $K_{r a}$ are the coefficients for the rotational eddy current and anomalous losses. The rotational hysteresis loss behaves very differently from its alternating counterpart. A rotational filed causes nearly twice the loss, compared to the loss produced by an alternating field with the same peak value at midrange flux density. However, at saturation the loss caused by a rotational field falls markedly to the levels well below that caused by an alternating field [11]. To model the rotational hysteresis loss, a formulation was proposed in [11], as expressed in (3).

$$
\begin{aligned}
\frac{P_{r h}}{f} & =a_{1}\left[\frac{1 / s}{\left(a_{2}+1 / s\right)^{2}+a_{3}^{2}}-\frac{1 /(2-s)}{\left[a_{2}+1 /(2-s)\right]^{2}+a_{3}^{2}}\right] \\
s & =1-\frac{B_{m}}{B_{s}} \sqrt{1-\frac{1}{a_{2}^{2}+a_{3}^{2}}}
\end{aligned}
$$

where $a_{1}, a_{2}, a_{3}$ and $B_{s}$ are coefficients. All coefficients displayed in (2) to (4) can be deduced from the data measured by the rotational core loss tester by curve fitting (1) and (2).

The core loss with elliptical B is predicted from the alternating and circularly rotating core losses by:

$$
P_{f e}=R_{B} P_{\text {rot }}+\left(1-R_{B}\right)^{2} P_{a l t}
$$

where $R_{B}=B_{m i n} / B_{m a j}$ is the axis ratio, $B_{m a j}$ and $B_{m i n}$ are the major and minor axes of the elliptical $\boldsymbol{B}$ locus.

The flux density loci at typical elements of the SMC motor yoke (point A shown in Fig. 2) and the laminated steel motor yoke (point B shown in Fig. 5) are shown in Fig. 8 and Fig. 9, respectively. It can be seen that the magnetic field in SMC motor is really 3-D and the magnetic flux density vector rotates in an elliptical pattern. In the laminated steel motor, the flux density vector rotates in an elliptical pattern, too, but within the lamination plane.

The distributions of stator core losses at no-load are shown in Fig. 10 and Fig. 11. In SMC motor, the core loss in the claws is greater than that in other parts of stator core because the amplitude changing of magnetic field is greater than that in other parts. In laminated steel motor, compared with Fig. 6, core loss in the yoke is greater than that in the teeth because the amplitude changing of magnetic field in the yoke is greater.

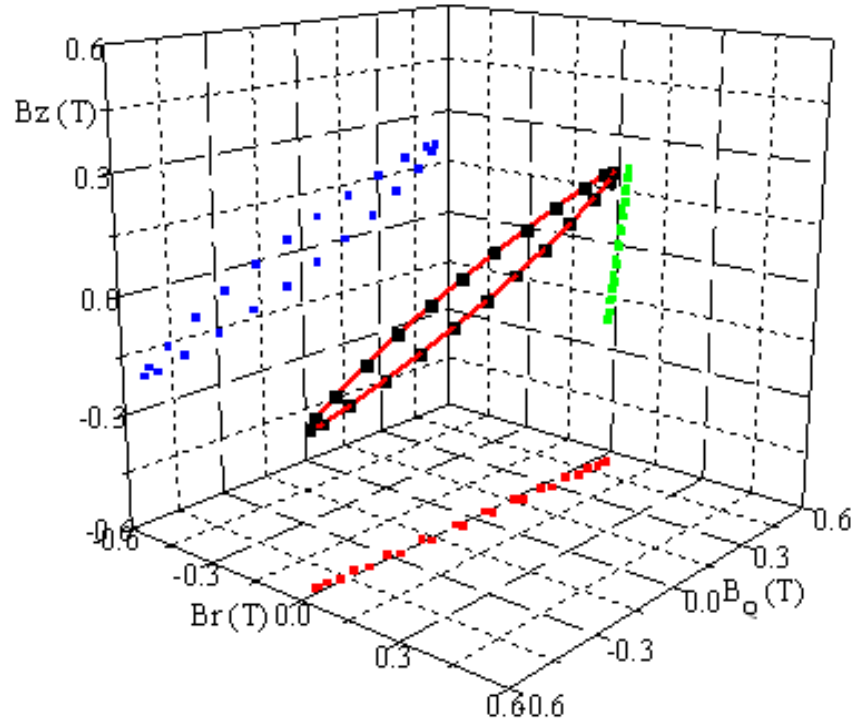

Figure 8. Flux density locus at a typical element of the SMC motor yoke 


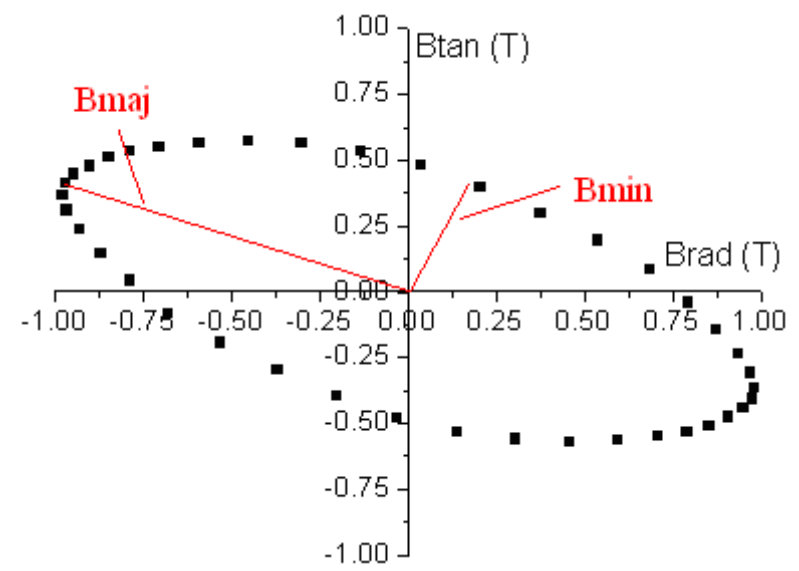

Figure 9. Flux density locus at a typical element of the laminated steel motor yoke

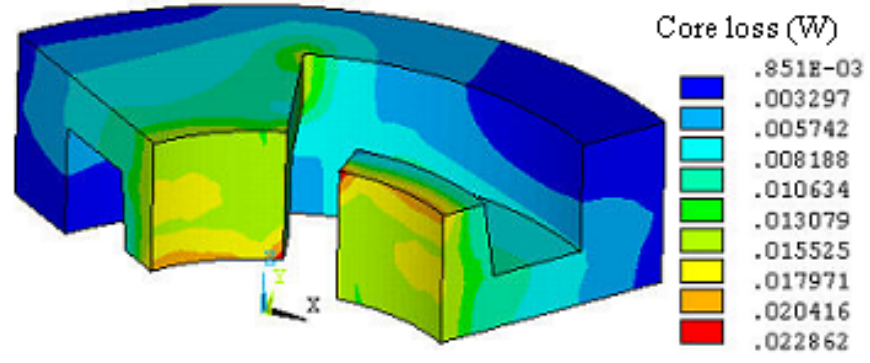

Figure 10. Distribution of core loss of the SMC motor at no-load

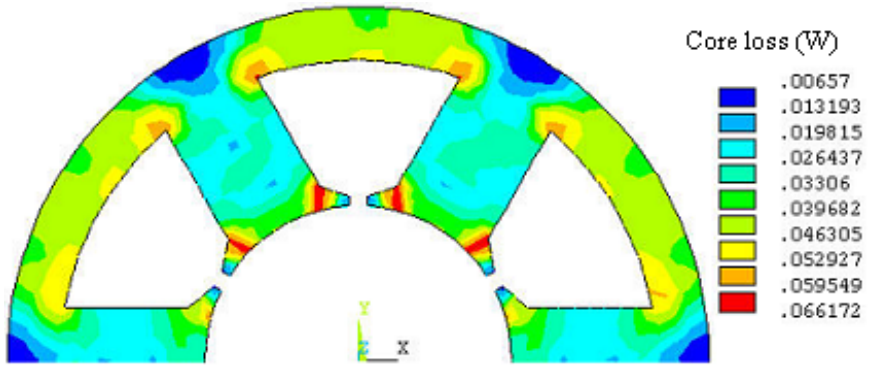

Figure 11. Distribution of core loss of the laminated steel motor at no-load

\section{COMPARISION OF RESULTS}

\section{A. $E M F$}

In SMC motor, the major path of the magnetic flux is along the north pole of the $\mathrm{PM} \rightarrow$ air gap $\rightarrow$ one claw pole $\rightarrow$ stator yoke $\rightarrow$ another claw pole $\rightarrow$ air gap $\rightarrow$ south pole of the $\mathrm{PM} \rightarrow$ rotor yoke to form a closed loop. If the leakage flux is neglected, the magnetic flux per pole per phase can be calculated as

$$
\phi_{\text {pole }}=B_{g} \tau_{g} l_{g}=B_{g} \tau_{g} L / 3=\frac{1}{3} B_{g} A_{g}
$$

where $B_{g}$ is the magnetic flux density in air gap, $\tau_{g}$ and $l_{g}$ are the pole pitch and air gap axial length per phase, respectively. $L$ is the axial length of the motor. The flux of all poles link with the phase winding in the transverse flux machine, so the magnetic flux linkage per phase per turn can be expressed as

$$
\psi=\frac{\phi_{\text {pole }}}{2} * 2 p=\frac{p}{3} B_{g} A_{g}
$$

where $p$ is the number of pole-pairs.

In the laminated steel motor, the magnetic flux linkage per phase per turn can be expressed as

$$
\psi=B_{g} A_{g}
$$

In this paper, $\mathrm{p}=2$, and two motors' EMF waveforms are shown in Fig. 12 and Fig. 13, respectively. It can be seen that the calculation results match very well with the measurement results. The SMC motor's EMF waveform is close to square wave, and the laminated motor's EMF waveform is close to sinusoid. These are in relation to the winding flux waveforms calculated in Fig. 4 and Fig. 7. The amplitude of SMC motor's EMF is about $2 / 3$ of that of laminated steel motor. This agrees with (7) and (8). When the number of poles is greater than 6 , the magnetic flux linkage per phase per turn of the transverse flux machine will exceed that of the radial flux machine.

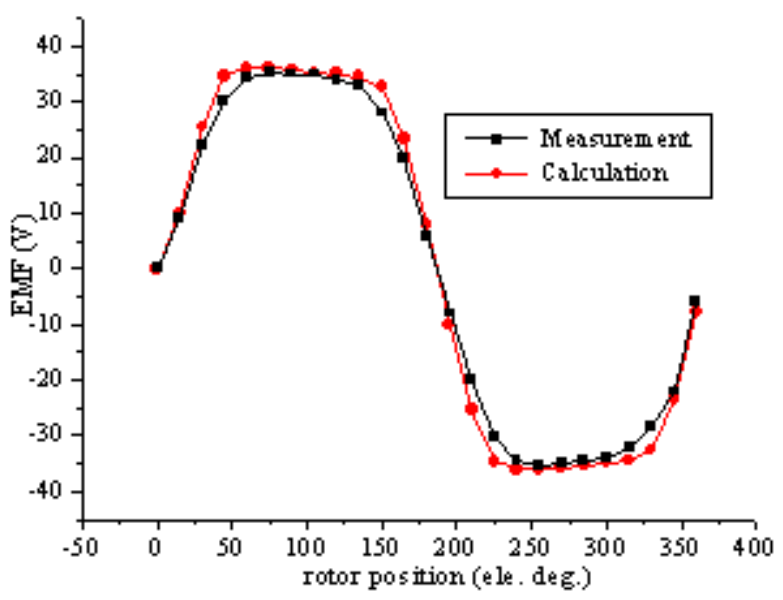

Figure 12. EMF waveform of the SMC motor (30 turns)

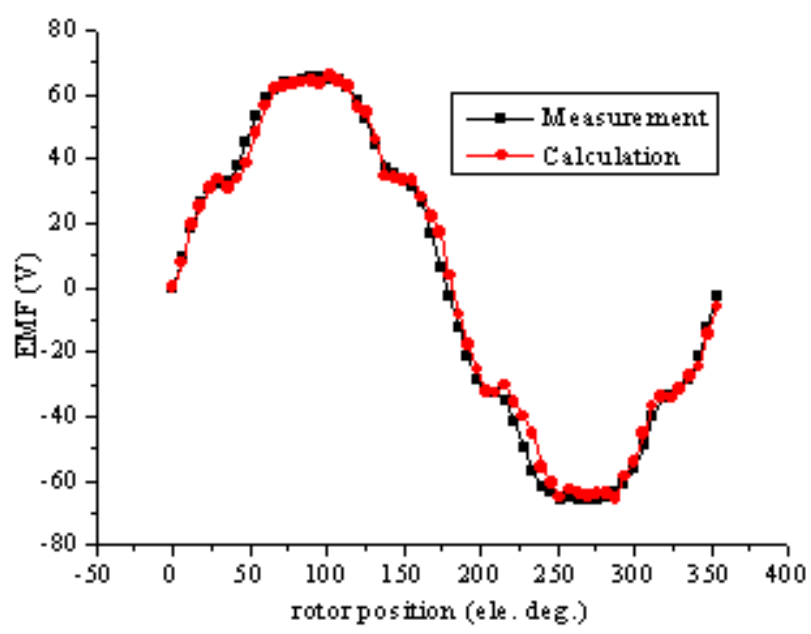

Figure 13. EMF waveform of the laminated steel motor (30 turns) 


\section{B. Core loss}

A testing bench is set up to measure the core loss at no-load generating operation. The core loss at no-load is measured by separating the core loss from the mechanical loss using the dummy rotor method, which includes two measurements. In the first measurement, the prototype is driven by the DC motor and the DC motor input power $P_{i n 1}$ and copper loss $P_{c u 1}$ are recorded. In the second measurement, a dummy rotor is used, which does not have permanent magnets. The DC motor input power $P_{\text {in } 2}$ and copper loss $P_{\text {cu2 }}$ are recorded again. Assuming that the core loss and mechanical loss in the DC driving motor can be taken as constant at each rotor speed, the difference $\left(P_{\text {in } 1}-P_{\text {cu } 1}\right)-\left(P_{\text {in } 2}-P_{\text {cu2 } 2}\right)$ gives the core loss $P_{f e}$.

The calculation and measurement results of core loss are compared in Fig. 14 and Fig. 15. Below 12krpm, the error is less than $10 \%$, but the maximum error is about $15 \%$ when the rotate speed is over $12 \mathrm{krpm}$. The possible reasons are: (1) loss coefficients derived from the rotational core loss data at low frequency may cause some errors when they are used in high frequency, (2) rotor loss cannot be distinguished from the measurement results.

At $20 \mathrm{krpm}$, the core loss of SMC motor is much greater than that of the $0.35 \mathrm{~mm}$ laminated steel motor. It is shown that the SMC material does not have predominance in performance compared with high quality electrical steel when the operation frequency is about $1000 \mathrm{~Hz}$. From our calculation, when the operation frequency is over $1500 \mathrm{~Hz}$, the SMC materials will have predominance in performance.

\section{Cost}

The price of $0.35 \mathrm{~mm}$ electrical steel is about $\$ 1300$ per ton, and SOMALOY ${ }^{\mathrm{TM}} 500$ is about $\$ 780$ per ton. In large-scale manufacture, SMC motors' core is made by a die, which do not have any material waste. But, in the manufacture process of laminated steel motors' core, more than $20 \%$ material will be wasted when the stator outer diameter is $78 \mathrm{~mm}$. On the other hand, the distribution coil used in laminated steel motor is more complicated than the global coil used in SMC motor. It means that more manual work is needed in laminated steel motor than in SMC motor. In a word, SMC motor has a greater advantage than laminated steel motor in cost.

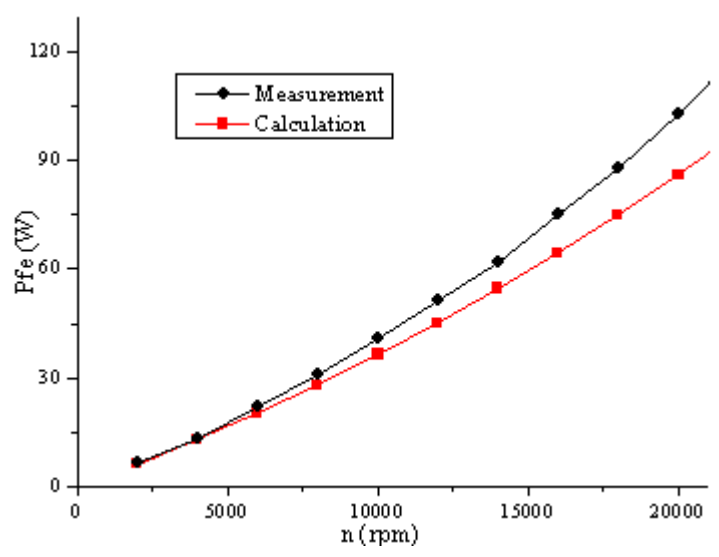

Figure 14. Core loss of the SMC motor

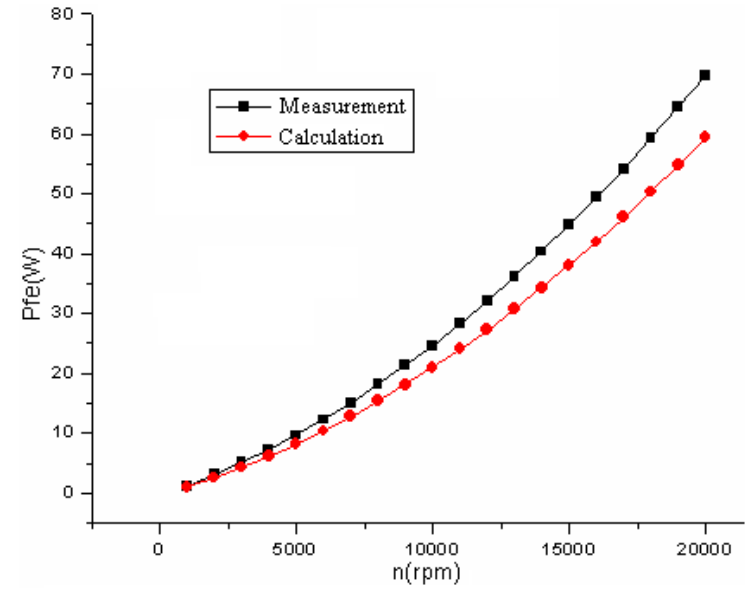

Figure 15. Core loss of the laminated steel motor

\section{CONCLUSION}

To verify the SMC material properties on high frequency and show the potential of the material, a high-speed PM motor with SMC core is manufactured in this paper, and another PM motor with the same dimension using laminated steel is also manufactured for comparation. The experiment results have testified the SMC material properties and the design methods used in both motors. It is also shown that the SMC materials should be used in the application when the operation frequency is greater than $1500 \mathrm{~Hz}$.

\section{ACKNOWLEDGMENT}

This work was supported in part by the National Natural Science Foundation of China under Grant No. 50477021 and the Excellent Doctor Thesis Foundation of Southeast University under Grant No. YBJJ0510..

\section{REFERENCES}

[1] Y. G. Guo, J. G. Zhu, P. A. Watterson, W. M. Holliday, and W. Wu, "Improved design and performance analysis of a claw pole permanent SMC motor with sensorless brushless DC drive,” Power Electronics and Drive Systems, 2003. PEDS 2003. The Fifth International Conference on, vol. 1, pp. 704-709.

[2] J. Cros and P. Viarouge, "New structures of polyphase claw-pole machines,” Industry Applications Conference, 2002. 37th IAS Annual Meeting, vol. 4, pp. 2267 - 2274.

[3] A. G. Jack, B. C. Mecrow, C. P. Maddison, and N. A. Wahab, "Claw pole armature permanent magnet machines exploiting soft iron powder metallurgy,” Electric Machines and Drives Conference Record, 1997, IEEE International, pp. MA1/5.1 - MA1/5.3.

[4] B. C. Mecrow, A. G. Jack, and C. P. Maddison, "Permanent magnet machines for high torque, low speed applications," Proceedings of International Conference on Electrical Machines, Vigo, Spain, September 1996, pp. 461-466.

[5] G. Henneberger and M. Bork, "Development of a transverse flux traction motor in a direct drive system,” International Conference on Electrical Machines, Helsinki, Finland, August 2000, pp. 1457-1460.

[6] Y. G. Guo, J. G. Zhu, P. A. Watterson, and W. Wu, "Development of a permanent magnet transverse flux motor with soft magnetic composite core," IEEE Transactions on Energy Conversion, vol. 21, no. 2, pp. 426434, June 2006.

[7] Y. Chen and P. Pillay, "Axial-flux PM wind generator with a soft magnetic composite core,” Industry Applications Conference, 2005. Fourtieth IAS Annual Meeting, vol. 1, pp. 231-237. 
[8] A. G. Jack, B. C. Mecrow, and C. P. Maddison, "Combined radial and axial permanent magnet motors using soft magnetic composites," Electrical Machines and Drives, 1999. Ninth International Conference on (Conf. Publ. No. 468), vol. 1, pp. 25-29.

[9] J. Cros, P. Viarouge, Y. Chalifour, and J. Figueroa, “A new structure of universal motor using soft magnetic composites,” Industry Applications, IEEE Transactions on, vol. 40, pp. 550-557, 2004.
[10] A. Jack, B. Mecrow, P. Dickinson, P. Jansson, and L. Hultman, "Design and testing of a universal motor using a soft magnetic composite stator," Industry Applications Conference, 2000. Conference Record of the 2000 IEEE, vol. 1, pp. 46-50.

[11] J. G. Zhu and V. S. Ramsden, "Improved formulations for rotational core losses in rotating electrical machines,” IEEE Trans. On Magnetics, vol. 34, pp. 2234-2242, July 1998. 